\title{
Are grandparents raising grandchildren receiving the services they need?
}

\author{
Karleah Harris', Gifty Ashirifi', Charlene Harris 3 , Jonathan Trauth ${ }^{4}$
}

\begin{abstract}
Grandparents play an important role in the upbringing of grandchildren and face increased levels of stress. Using family stress theory, the present study examined the effectiveness of service programs for grandparents raising grandchildren. Data were collected through focus group interviews and audiotaped from a sample of four custodial grandparents living in Ohio U.S.A. To better understand grandparents that are raising their grandchildren, we asked the following questions: 1) What support is needed for grandparents raising grandchildren? 2) At what stage is the support needed: beginning, middle or late stages of caregiving? 3) What are grandparent caregivers' perceptions of service programs? The audiotape was transcribed verbatim and analyzed for themes relevant to the research questions. The findings from these questions are examined and implications discussed.
\end{abstract}

\section{Article History}

Received: 03 February 2021

Accepted: 03 July 2021

\section{Keywords}

Grandparents;

Grandchildren

Grandfamilies; Kinship care;

Family supportive programs

\section{Introduction}

Today, many grandparents have taken on the role of raising their grandchildren (Bigner \& Gerhardt, 2019). When grandparents raise their grandchildren, they offer nurture instructions, morals, ethics, wisdom, backup support for parents, and values to their grandchildren (Bigner \& Gerhardt, 2019). Grandparents may also provide support, attention, time, special outing, and privileges to their grandchildren during divorce (Brooks, 2013). The roles do not have clear-cut boundaries or definitions but can be viewed as having diverse aspects with regards to the nature of each grandchild relationship (Bigner \& Gerhardt, 2014).

In some cases, grandparents accept the responsibility of raising their grandchildren for cultural reasons (Lewis, Boyd, Allen, Rasmus, \& Henderson, 2018). However, others accept the responsibility to raise their grandchildren because they believe it is the right thing to do compared to the alternatives, such as using the foster care system (Peterson, 2018). Grandparents contribute immensely to the development of our society by alleviating the expenses associated with the placement of children in foster care or nonkin households. In some instances, some grandparents go back to work to provide adequate support and needs, while others take early retirement to take care of their grandchildren (Gardiner, 2015). Experiential research has revealed the need for assistance for grandparents raising grandchildren and others involved in kinship care (Collins, Fruhauf, \& Bundy-Fazioli, 2016; Lee \& Blitz, 2014; Dunn \& Wamsley, 2018). In response, many service programs, both public agencies and non-governmental organizations, have emerged to help these grandparents. With such efforts being directed towards these programs, there is a need to determine whether these programs are helping grandparents raising grandchildren (GRG). The current study aimed to explore GRG's perceptions about these service programs, identify their everyday needs, the stages at which they are needed, and factors that can ensure self-sustenance. It is important to

\footnotetext{
${ }^{1}$ University of Arkansas at Pine Bluff, Department of Human Sciences, Pine Bluff, USA e-mail: karleah.harris@gmail.com, ORCID: https://orcid.org/0000-0001-7243-4762

2 Indiana University; Purdue University Indianapolis, School of Social Work, Indianapolis, USA, e-mail: justashirifi@gmail.com, ORCID: https://orcid.org/0000-0002-6103-2618

${ }^{3}$ State University of New York at Oswego, Department of Human Development, Oswego, NY, USA, e-mail: charlene.harris@oswego.edu, ORCID: https://orcid.org/0000-0002$\underline{27974791}$
}

${ }^{4}$ Central State University, Department of Social and Behavioral Sciences. Wilberforce, USA e-mail: jtrauth@centralstate.edu, ORCID: https://orcid.org/0000-0001-97925584 
understand the family systems where grandparents are raising their grandchildren. This study uses the family stress framework to help bring awareness and to better understand such families.

Roben Hill (1958) proposed the ABC-X model and the family stress theory "to explain why some families struggle in response to stress whereas other families thrive" (Smith \& Hanon, 2017, p.129). Other researchers later modified the ABC-X model (Boss, 2002; McCubbin \& Paterson, 1983; Patterson, 1988). Drawing from the family stress theory, Sands and Goldberg-Glen (2000), found low stress when they receive support from their community and family. Sands and Goldberg-Glen (2000) mentioned that African Americans tend to grandparent caregivers than Whites. In comparison, GRG reflects a multicultural perspective in our society. According to Peterson (2018), custodial grandparents tend to be American Indian, Alaskan Natives, and African Americans; however, evidence shows that African Americans grandparents are more involved in raising their grandchildren than any other ethnic group.

This study will help to understand the perspectives of grandparents raising grandchildren, their views and experiences of service programs, and the coping and adaptive strategies they use in overcoming family stressors by giving in-depth information about the phenomenon. Therefore, our study will answer the following question. 1) What support is needed for grandparents raising grandchildren? 2) At what stage do GRGs need support: beginning, middle or late stages of caregiving? and 3) What are grandparent caregivers' perceptions of service programs? The results of this study will be used to help create more effective programs for grandparents who are raising their grandchildren and extend the literature on grandparenting.

\section{Literature Review}

Research has shown in the U. S. that the number of grandchildren living in grandparent-headed households in 1970 was about 3 percent (Ellis \& Simmons, 2008). By 2011, this number escalated to about 7 percent although, this percentage reduced to 6 percent in 2012 (Ellis \& Simons, 2008). In 2018, 8 million grandchildren lived in households headed by grandparents, and 2.7 million parents were primary caregivers for grandchildren. A classic study by Casper and Bryson (1998) explained five kinds of grandparent-maintained households namely: (1) both grandparents in residence, (2) some parents present and both grandparents in residence, (3) no parents present and grandmother in residence, (4) some parents present and grandmother in residence, (5) no parents present and grandfather only in residence. Some researchers refer to GRG as kinship caregivers (Monahan, Smith, \& Greene, 2013). Kinship care is defined as circumstances where blood relatives, godparents, or close family friends care for children on a full-time basis. Kinship caregivers tend to be older, single, unemployed, poor, and less educated (Casey, 2012). Two major kinds of kinship care exist (1) informal/private and (2) formal public. Informal or private kinship in cases where extended family members raise children without the involvement of child protective services Casey, 2012). Public or formal kinship care includes the involvement of the child welfare system and formal placement of children with their family members. In some cases of public kinship care, the child remains in legal custody of the state but is placed (fostered) with their relatives. In Ohio, there are 86,502 grandparents raising grandchildren out of the total of 117,000 children being raised by kinship caregivers (Ohio Grandfacts, 2021). For every child being raised by kinship caregivers in foster care, about 34 children are being raised outside of the foster care system. The prevalence of formal and informal kinship care is worth mentioning because being a formal kinship care or establishing legal adoption, guardianship or custody enables caregivers to access services such as health care, school enrollment, daycare and sports activities as well as obtain affordable housing (Cooper, 2012). This means that more informal kinship caregivers are raising children in Ohio without the needed support, and the number of informal caregivers continues to increase, according to researchers (Amorim, Dunifon, \& Pilkauskas, 2017). Apart from the time and financial obligations associated with the process of adoption, which can be a problem for grandparents, many grandparents avoid adoption because it could negatively impact the family dynamics and terminate parental rights (Cooper, 2012). Gibson and Singh (2010) proposed de Facto custodian legislation as an approach to help informal GRG. De facto custodian legislation would allow informal grandparent caregivers an option to present their caregiving history at custody hearings since many grandparents do not have legal custody of grandchildren. 


\section{Challenges Facing Grandparents Raising Their Grandchildren}

Grandparents face several realities following the decision to become second-time parents to their grandchildren. Researchers who study this phenomenon have indicated challenges related to role conflict (Backhouse \& Graham, 2013), health problems (Butler \& Zakari, 2005; Grinstead, Leder, Jensen, \& Bond, 2003), finance issues (Collins, 2011), legal issues (Van Etten \& Gautam, 2012), and psychological well-being of both the grandchildren and the grandchildren involved. Landry-Meyer and Newman (2004) conducted a study and reported that grandparent caregivers have the challenge of role timing, role ambiguity, and role conflict. Additionally, GRG experience psychological concerns about themselves and the grandchildren they are raising. Some grandparents may worry about being better parents to their grandchildren, especially if they feel that they failed with their first experience (Dolbin-MacNab, 2006). Others may worry about their health and physical wellbeing whether they will live long enough to continue providing care for their grandchildren until they are old enough to gain their independence. Grandparents can also worry about the emotional and psychological problems of their grandchildren and be concerned about how they are going to turn out to be when they grow up. GRG is also associated with grief due to high levels of depression and stress (Backhouse \& Graham, 2013). In another study conducted by Rausch (2016), maintained that housing is one of the crucial challenges of GRG as well.

Some GRG may not have access to affordable housing programs due to their legal relationship status with their grandchildren. Using a nationally representative sample of 700,000 households, Fuller-Thomson and Minkler (2003) researched grandparents' housing issues and the realities facing grandparent caregivers who are renters. Fuller-Thomson and Minkler (2003) reported that, out of the total number of GRG their grandchildren in the United States, 26 percent were renters. Many renters lived below the poverty line and used 30 percent or more of their income on rent. Fuller-Thomas and Minkler (2003) added that GRG who are renters have a unique vulnerability, and this vulnerability needs more investigation and intervention. The researchers called for the creation of public policies to address housing vulnerability among grandparents raising grandchildren. Rausch (2016) conducted a study that looked at grandfamily housing focusing on the pilot project in Kansas City, Bronx, and Phoenix. Rausch (2016) found that grandparents raising grandchildren who participated in these pilot programs still found it hard to make ends meet, which hindered their ability to benefit from the program entirely. In addition, eligibility criteria of having legal custody of the grandchildren these grandparents are also raising could serve as a barrier to the program. Rausch (2016) added that these affordable housing staff members must treat residents with respect and be committed to enhancing the well-being of GRG.

\section{Coping and Adaptation Process}

The process of caring for grandchildren fulltime can be problematic for both grandparents and the grandchildren because they both have to find ways to make things work in the new environment of caregiving and care for themselves. They both have to deal with new roles and new identities, and they have to find ways to cope and adapt to caregiving. Coping and adaption are closely related, and Pandialagppan and Ibrahim (2018) explained the family adaptation theory noting that it is a fluid process where families adjust and expand efforts to tolerate as well as reduce conflict and stress within families. Pandialagppan and Ibrahim (2018) posited that grandparents raising grandchildren take on multiple roles and experience stress with adaptation and parenting demands. Bailey, Letiecq, and Porterfield (2009) studied 26 GRG and how grandparents cope and adapt. They found out that these grandparents are able to cope using strategies such as shifting their roles, identities, relationship, resources, and the way they perceive the situation. According to the researchers, further studies are needed to identify and support coping strategies that GRG use to adapt and cope within the complex family transitions and stressors in which they find themselves. In another study, Porterfield (2007) utilized McCubbin and Patterson's (1983) Double ABC-X model and focused on the coping and adaptive strategies of GRG. In the ABC-X model, Porterfield (2007) noted that in the family, A reflects demands, B reflects resources, C reflects perception, and $\mathrm{X}$ reflects the family crisis. Therefore, by using the family adaptation as a central concept, the Double ABC-X model attempts to explain the outcomes of a family effort to overcome crises and attain a balance after those crises. Porterfield (2007) maintained that coping and adaptive strategies could be affected by 
external, internal, cultural, historical, economical, developmental, hereditary, psychological, and structural factors. These findings were consistent with the results of the research by Bailey et al. (2009). The results suggested that grandparents must deal with shifting roles, identity, relationships, community relationships, resources, and perceptions. The author added that grandparents caring for grandchildren must delay retirement and utilize their resources to engage in primary caregiving.

\section{Available Resources}

Recently there has been an increase in services and service programs for grandparents raising grandchildren. GRG can now apply for assistance and receive benefits from programs such as Temporary Assistance for Needing Families (TANF), Supplemental Nutrition Assistance Program (SNAP), and Medicaid (Child Welfare Information Gateway, 2016). Through non-profit advocacy organizations such as Generations United, public policies that address the needs of grandparents raising grandchildren are changing and expanding to bring more assistance and services to such families. According to the American Association of Retrieved Persons (AARP) several resources in Ohio can benefit grandparents raising grandchildren. These programs include, The Area Agency on Aging (for referrals on legal assistance), The Ohio Grandparent Kinship Caregiver Coalition, Ohio Department of Job and Family Services (2017) (provides at toll-free helpline), The Ohio Family Care Association, and The Kinship Caregiver Navigator Grant-Public Children Services Association of Ohio.

One of the major challenges facing GRG is that they need education on where and how to find community services and service programs. Gardiner (2015) noted that grandparents raising their grandchildren could benefit from family life education as a resource that provides grandparents with education regarding finding resources. In addition, Gardiner (2015) suggested that collaboration among service organizations may be beneficial and enable GRG to reach the services they need. As a result, GRG can have resources available to them from different sources, including the government, non-profit organizations, state and federal programs. The Supporting Grandparents Raising Grandchildren Act was passed to help grandparents raising their grandchildren (Generation United, 2018). This new Ohio law will establish a council that will support the affairs of grandparents and other family members who are raising grandchildren. This council will be overseen by the Department of Human Services (Generation United, 2018).

Despite the availability of resources and service programs, Sutphin (2015) reported low participation in state services by kin caregivers involved in raising grandchildren. Low usage of state services occurs because kinship caregivers do not want to interact with child welfare agencies. In addition, some services users, including grandparent caregivers, report being disrespected and mistrusting child welfare agencies (Sutphin, 2015). Therefore, these state service agencies must train their employees to treat service users with respect and remain consistent with the quality of services to gain trust from their service users (Sutphin, 2015).

\section{Family Stress Theory}

Boss, Bryant, and Mancini (2017) defined family stress as "a disturbance in the steady-state of the family system" (p. 2). Family stress is also referred to as a disturbance that takes place in family life organization and process (White, Klein, \& Martin, 2015). Hill (1958) proposed the ABC-X model of family stress known, and it is the foundation upon which the family stress theory is formed, which helps us to illustrate the processes in which individuals and families experience stressor events. The revised ABC-X model was modified by Boss (2002) to include the coping component. At the same time, McCubbin and Patterson (1983) modified the ABC-X model known as the double ABC-X to reflect additional stressors. Later, Patterson (1988) included the family adjustment and adaption response model (FAAR), thus, focusing on the family's adjustment after a stressor. Arditti (2015) highlighted that the "modern variations of the family stress theory often focus on intervening psychological and relational process that determines in part how a particular stressor event connects with family outcome" (p.6). Sands and Goldberg-Glen (2000) used stress the stress theory to explain GRG relationships. The study was conducted in the U.S. and consisted of 129 grandparents (i.e., 32 middle age 50-59 African American, 32 White and 34 older 60 to 90 
African American and 31 White). The participants were recruited from various community organizations e.g., churches, social service agencies, Big Brother/Big Sister clubs, grandparent support groups, and public and private schools and preschools. Sands and Goldberg-Glen (2000) found "a correlation between the grandchildren's psychological and physical problems and the grandparents' stress" (p.104). In another study, Whitley, Lamis, and Martin (2016) investigated 679 African American grandmothers between 33 and 83 years old and raising their grandchildren. Whitley et al. (2016) showed that 406 of the grandmothers in their study had a high school degree, while 273 did not. At the same time, only 279 of the grandmothers were employed, whereas 400 were retired or unemployed. The results revealed that the interventions that they provided to the grandmothers who were displaying low verses. High stress contributed to a reduction in psychological distress. Additionally, the "grandmothers with high stress at baseline appeared to have benefited more from improved access to family resources, as indicated with reductions in distress, compared with grandmothers with low stress"' (p. 574).

\section{Purpose of the Study}

The purpose of our study is to examine the perspectives of grandparents who are raising grandchildren and their views and experiences of support programs in Ohio. To better understand grandparents that are raising their grandchildren, we answer the following questions:

1) What support is needed for grandparents raising grandchildren?

2) At what stage is the support needed: beginning, middle or late stages of caregiving?

3) What are grandparent caregivers' perceptions of service programs?

\section{Method and Participants}

In order to attain rich in-depth, descriptive data on the perceptions and experiences of grandparents raising grandchildren, we used a qualitative approach. Grandparents were recruited through the Kinship Navigator Program (KNP) of Ohio which provides support services to relative or kinship caregivers. Grandparents willing to participate in the program met at the study site on a scheduled date for the focus group interview. Prior to the beginning of the focus group interview, the objectives of the study were explained to the participants and they were provided with the consent forms. The focus group interviews were audio-recorded and transcribed verbatim for thematic analysis. The session was about 90 minutes long, and each participant received a gift card and refreshments from the KNP staff. The participants were asked a variety of questions regarding kinship caregivers. The researchers were guided by Braun and Clarke's (2012) six thematic analysis procedures, including familiarizing yourself with the data, generating initial codes, searching for themes, reviewing and defining before reporting the themes. The thematic analysis broke down the data into individualized concepts, labeled by content and organized into more prominent themes in response to each of the research questions; 1) What support is needed for GRG? 2) At what stage do GRGs need support: beginning, middle or late stages of caregiving? And 3) What are grandparent caregivers' perceptions of service programs? Ravitch and Carl's (2016) three-step process of "data organization and management, immersive engagement, and writing and representation" (p. 238) were used to interpret the data. Trustworthiness was established through discussions between the researchers to refine and clarify themes. Disagreements around themes were reviewed and clarified.

The participants in this study consisted of four grandparents. Other grandparents were recruited to participate, but only four showed up for the focus group interview. One of the four grandparents in this study was at the beginning stages of raising their grandchildren, while the others had as much as 18 years of grandparenting experience. Some of them were informal caregivers who did not have a legal relationship with the grandchildren they were raising. Also, others were formal caregivers with full custody of the children that they were raising. Some of them were still employed, while others were stay-at-home parents that are raising their grandchildren. They also had varying income levels ranging from middle to low and even below the poverty line. All of the participants in this study were living in Ohio, females and NonLatino White. To maintain the confidentiality of the participants, the results below were presented in an aggregated summary form, and pseudonyms were used when referring to individual participants. 


\section{Results}

The first interview questions focused on the types of ongoing support needed for grandparents who are raising grandchildren? All four participants agreed that they need varied support, including financial and emotional support. Our results revealed that service programs for kinship care are most effective for grandparents who are raising grandchildren. We also learned from our participants that they need support at all stages (beginning, middle, and end) of caregiving. Additionally, our study shows that grandparents raising grandchildren experience stress and need family and community support and confirm with (Pandialagappan \& Ibrahim, 2018; Sands \& Goldberg-Glen, 2000) work. Thus, our results showed that the family stress framework is associated with grandparents raising grandchildren as they experience stress (i.e., financial hardship, challenges) in their caregiving roles. Some of these areas that they need support include legal assistance, support groups, affordable public housing, and social support. Further details of our findings are discussed below.

\section{Support Groups}

All of the participants reported that they needed support of others. They maintained that they need support groups to share ideas, recommendations, education, and emotional support since they are going through the process of raising their grandchildren. One of the participants said:

"this is what we need. What we need is each other to talk to about because we are all in the same calling, in the same boat, we are like in the same journey."

All four participants also added that they need service programs to assist them with the many challenges they face in raising grandchildren. Accessing children's clothing was a prominent theme during the interviews, and three of the participants noted that children grow very fast and easily outgrow their clothes. One of the grandparents also added that she needed after school programs for her grandchildren to help with mathematics. The after-school programs enable grandchildren to get caught up with the school curriculum. Due to the abusive situations that some grandchildren were in before living with their grandparents, one also wanted counseling services for the grandchildren. Two of the grandparents mentioned that some of the grandchildren they are raising have Attention-deficit/hyperactivity disorder (ADHD) and most of their children are emotionally unstable. Support for extra-curricular activities, including sports programs and summer camps, was also among the ongoing needs of two of the grandparents. One of the participants said:

"I need "support to help my grandchild with extra curriculum activities."

\section{Legal Assistance}

All of the participants reported that they need assistance in the legal process of gaining custody or guardianship for the grandchildren they are raising. All four of the grandparents posited that the legal process could be time-consuming and costly. In addition, two reported that they have challenges with attaining of custody for the grandchildren they are raising because the parents refuse to give them custody. Three of them reported not accessing public assistance because they do not have legal custody over the grandchildren they are raising. One participant said:

"I have no spouse, no second income it's just me and this lady and she helped me crib, a car sit, she listened. She helped me with like all the legal stuff I'm like cos I don't know what I was doing, like I knew what I was doing but I didn't. So, she was a great support but then it's like I'm kind of stuck in the middle now because it's a children services case and mom still want custody back but and I can't get any money at all."

Another participant said:

"I think a huge part of this and the stressfulness you know where can we get more support you know on the end. Ahh you know sharing our frustrations of we have these babies we're taking care of some of us don't even have legal rights to them."

\section{Affordable Public Housing}

One of the four grandparents reported the need for affordable housing services. She explained that 
the inability to access affordable housing leads to frequent interruptions in living situations, which can be difficult with grandchildren. Therefore, it would be better if there was affordable public housing for grandparents who are raising grandchildren. It would provide grandchildren with stable housing. Three grandparents agreed that once they assumed custody of their grandchildren, they were essentially responsible for housing---there was no follow up on their living situation. In many cases, grandparents did not have stable housing and continue to move around with the grandchildren they are raising. One of the participants stated, "I've been depressed since I lost my home. I was living in a van with three kids at the park cause I was scared of my son." Another participant revealed:

"...I think that would be helpful is that like parents or caregivers or grandparents, there should be a program to where they should be able to maybe like have a home, the kids know oh the is my home and I'm not going anywhere. I don't have to move no more, and then once the kids are grown; they can give it back to the state."

Policymakers should follow the recommendations made by researchers and develop affordable housing policies that will alleviate GRG of this burden to enhance the quality of life and well-being of grandfamilies.

\section{Informal Social Support}

Two of the grandparents shared that they have family and friends who give them some emotional support sometimes. However, when it comes to financial needs, they bear the full burden. One of the grandparents maintained that if family and friends could take the grandchildren sometime to provide respite opportunities for GRG, this would be very helpful. One also shared that it would be great if they could receive some support from the other grandparents of the children. However, they maintained that interference from the parents of the grandchildren causes a lot more harm than good because most parents are not consistent in their offering of support. One of the participants said:

\footnotetext{
"They say they'll come but they don't. ...So that now they stop the weekend visits cos he used to go there every weekend. He never missed meeting... halfway and now they stopped it and my grandson is run into depression...and we had a big old party for him for Halloween/birthday party cause his birthday is on the 25th and he didn't know that his big brother was coming down and then when Mary pulled him to the backyard on the side then he says that's my big brother, my dad. And he's got that same one. I think they need more support like that too. You know."
}

The second research question asked at what stage grandparents raising grandchildren need support, i.e., in the beginning, middle or late stages of caregiving. All four of the participants of the focus group interview agreed that they need support at all stages. They all insisted that it is essential for them to have someone (e.g., case manager) who is trustworthy and reliable, especially during difficult times. One of the participants said:

"You should be able to have that support person that you can trust capital letters TRUST that you could call on and say hey I'm having this issue or they can you give me just five minutes of your time and talk to me, or hey can we meet up somewhere and let me show you how their behaviors is and can you direct me."

Three participants added that they need all kinds of support, including clothes, because they grow very fast and quickly outgrow their clothes. Three grandparents agreed that they could not get their grandchildren registered for any of these extra-curricular activities due to limited income. One of the grandparents stated that she does not like the school in her area, so she considered homeschool or a private school for her grandchild because most of the children who attend the school are from low-income and dysfunctional homes. She was concerned that her grandchild would be negatively influenced by other children from dysfunctional homes at her current school. Another grandparent immediately recommended a different school that her grandchildren attended and added that the school is designed to work well with children from low-income families who are high-risk students. She said the school has summer school and counseling programs for the students as well.

The third research question focus on what are grandparents' perceptions of service programs? The grandparents shared that the KNP has been beneficial to them, and they appreciate all the support they have received from the program. According to the grandparents, KNP has assisted them with education, connecting them to community resources and accessing tangible goods such as baby cribs, car seats, pull- 


\section{Karleah HARRIS et al.}

up diapers, and clothes. One of the grandparents shared that she received support from the KNP to gain custody of her grandchild. While sharing about the KNP, the grandparents focused on a particular employee of the kinship program known as "Bev." All four participants shared how wonderful she has been to them and the tremendous support she has been to them through the KNP. For participants to access the service program, they needed someone they can trust and rely on, and "Bev" was labeled as this person. The grandparents described "Bev" as kind, patient, knowledgeable, reliable, and accessible. They added that some of the organizations that run service programs for GRG are not easy to access. According to participants in this study, some organizations say they will come, but they never show up. Even though the KNP has been extremely helpful to the grandparents, they also agreed that the program has its limits. Some of the participants said:

"Kingship can only do so much they can help us with certain things; she gets us what she can. She did get Maxine she did get us a car sit. Bev helped me she helped me a big supply of pull-ups and a new car seat."

Another participant shared:

"I know that I have received help from kinship from Bev for probably eighteen years... she's been nothing but support; whether emotional, if I need something for my son or one of my grandkids umm. It's an amazing program kinship is, and I don't know what I would have done without Bev. Yeah, Bev has been a huge support for me."

\section{Discussion}

We investigated GRG and service programs. At the same time, we used a qualitative approach and three main questions.

Our first research question addresses the ongoing support needed GRG. The findings of this study suggest that GRG's unmet needs include support groups, service programs, legal assistance, affordable housing, and emotional support from family and friends. Our results also showed that some service programs like the kinship navigator program for grandparents are effective and helpful. The participants shared their perspectives of what makes service programs effective. These results are consistent with existing literature on the ongoing needs of grandparents raising grandchildren and those providing foster care for grandchildren. Even though the focus group interview was not organized to function as a support group, participants could share and talk about their challenges in that safe environment and receive feedback from other participants who have had the same experience and were knowledgeable about what to do in such circumstance. Thus, we further clarified how important and beneficial support groups could be to grandparents raising grandchildren.

Many factors such as the financial burden, time, and negative family dynamics make it difficult for grandparents to gain legal custody of the grandchildren they are raising (Cooper (2012). Without legal custody, GRG's ability to access public assistance is impeded. However, this study highlights the need for increased support services for GRG. Without increasing support, grandparents will continue to experience the stressors associated with the care of grandchildren which can have adverse outcomes for all involved. Social workers must engage in policies and legislation at the state level, to increase funding for GRG and by other relatives to improve child well-being outcomes.

As attested by other researchers such as Rausch (2016), housing continues to be one of the crucial challenges of GRG. For many grandparents providing a stable home for their grandchildren is important as unstable housing situations can impede custodial placement. However, many barriers exist including, rising costs associated with rentals and mortgage rates which make access to affordable housing out of reach for GRG.

Our second research question addresses what stage grandparents are raising grandchildren need support, beginning, middle or late stages of caregiving. All the grandparents agreed that they need support throughout the three stages (i.e., beginning, middle, end) of caring for and raising their grandchildren. Access to support at the beginning stage could be critical for both grandparents and grandchildren. As reported by the participants in this study and other researchers, most grandparents get called into the service of raising grandchildren without prior notice, or initial training. Most grandparents insisted that 
even though they accepted the call to raise their grandchildren, they did not know how to attain custody of the grandchildren, access services or obtain information. Therefore, having access to support at the beginning stage to eliminate the confusion of not knowing what to do could be very helpful. In addition, most public support programs require grandparents that are raising grandchildren to have legal custody or guardianship prior as an eligibility criterion for receiving services. Without the legal relationship between grandparents and the grandchildren they are raising, grandparents are not eligible to receive public support for housing in New York (Boss et al., 2017). Grandparents' ability to receive services at the beginning stage of raising grandchildren is again crucial because they mostly are not prepared to take care of grandchildren when they get called into raising their grandchildren. Unexpectedly, they have to deal with additional financial and other responsibilities related to raising their grandchildren which can be overwhelming. Hence receiving services and support at this stage could bring them tremendously much needed help. In the past few years, several funding bills have been passed that could be helpful to GRGs in the state of Ohio.

Our third research question asked about grandparents' perceptions of service programs. Overwhelmingly, grandparents stated that the personality traits of the employees working with organizations that provide services to grandparent caregivers are critical to the accessibility of the program by the target population, as well as the impact and the general success of the program. The grandparents who participated in this study maintained that it is important to have a program employee whom you can trust and whom you can call in difficult times when you need someone to talk to for support and direction. Unfortunately, because of the stigma associated with grandparents caring for grandchildren, many grandparents may not even want to engage with service programs because of the stereotypes and stigma associated with their situation. Therefore, program staff must be trained to treat clients to ensure program accessibility and the success of their programs.

\section{Recommendations for Future Research}

The study shows that support groups and services programs that help grandparents raise grandchildren are still unmet. Therefore, future research should focus on grandparent caregivers' unmet needs and the barriers that prevent them from receiving support. Access to support groups and services during the early stages when the grandparents get the grandchildren is crucial. We should put more effort into strengthening the support for grandparents at these early stages. In addition, organizations that work with grandparent caregivers should emphasize the importance of interpersonal communication for working with vulnerable populations such as grandparents raising grandchildren. In addition, creating affordable public housing for grandparents raising grandchildren where there are non-existent is important. This could help to enhance the quality of life for both grandparents and the grandchildren they are raising.

\section{Limitations of The Study}

There are a number of limitations to the study. First, the small sample size (4) are not generalizable to all grandparents. Future studies should recruit a large sample of grandparents this will allow for more generalizability of study findings. Second, participants of this study were all white females (grandmothers) residing in Ohio. Grandfathers raising their grandchildren were not included in this study, thus we cannot account for parental experience of grandfathers. Additionally, this study consists of a homogenous sample of grandparents residing in the state of Ohio. Other states may have different regulations, support programs and policies for GRG.

\section{Conclusion}

Grandparent-headed households and grandparent caregiving are fixtures in our society. Our research findings add to the existing literature on grandparents raising grandchildren and expands the understanding of this phenomenon based on the research objectives. Despite the size of the sample, our paper can be expanded to focus on services that grandparents need while raising their grandchildren as well as to improve services for grandparents. Policy changes are required to ensure adequate resources and 


\section{Karleah HARRIS et al.}

support for both grandparents and the grandchildren they are raising. Our research shows that even though we are making progress towards supporting the needs of grandparent caregivers, more support is needed.

\section{Declarations}

Acknowledgements: The authors are grateful to Dr. Anthony James for his support and assistance in the data collection. We also want to thank Dr. Alec Sithole for his helpful comments on earlier versions of this article and all the participants in this study.

Authors' contributions: The authors contributed equally to this paper.

Competing interests: The authors declare that there was no conflict of interests.

Funding: Not applicable.

\section{References}

American Association of Retrieved Persons (AARP). Grandfacts state fact sheet for grandparents and other relative raising children. Retrieved from https://www.aarp.org/content/dam/aarp/relationships/friends-family/grandfacts/grandfacts-ohio.pdf

Amorim, M., Dunifon, R., \& Pilkauskas, N. (2017). The magnitude and timing of grandparental coresidence during childhood in the United States. Demographic Research, 37, 1695-1706. https://doi.org/10.4054/DemRes.2017.37.52

Arditti, J. A. (2015). Family problems: Stress, risk, and resilience. London: John Wiley \& Sons.

Backhouse, J., \& Graham, A. (2013). Grandparents raising their grandchildren: Acknowledging the experience of grief. Australian Social Work, 66(3), 440-454. https://doi.org/10.1080/0312407X.2013.817595

Bailey, S. J., Letiecq, B. L., \& Porterfield, F. (2009). Family coping and adaptation among grandparents rearing grandchildren. Journal of Intergenerational Relationships, 7(2-3), 144-158. https://doi.org/10.1080/15350770902851072

Bigner, J. J., \& Gerhardt. C. (Ed.). (2014). Parent- child relations: An introduction to parenting (9 ${ }^{\text {th }}$ Ed.). Upper Saddler River, NJ: Pearson.

Bigner, J. J., \& Gerhardt. C. (Ed.). (2019). Parent- child relations: An introduction to parenting (10 ${ }^{\text {th. }}$ Ed.). Upper Saddler River, NJ: Pearson.

Boss, P. (2002). Family stress management: A contextual approach $\left(2^{\text {nd }} \quad\right.$ Ed). Thousand Oaks, CA: Sage. https://doi.org/10.4135/9781452233895

Boss, P., Bryant, C. M., \& Mancini, J. A. (2017). Family stress management: A contextual approach. Thousand Oaks, CA: Sage. https://doi.org/10.4135/9781506352206

Braun, V., \& Clarke, V. (2012). Thematic analysis. In H. Cooper (Ed.), APA Handbook of research methods in psychology: Vol. 2. Research designs (pp. 57-91) Washington, DC: American Psychological Association. https://doi.org/10.1037/13620-004

Brooks, J. (Ed.). (2013). The process of parenting. New York, NY: McGraw Hill.

Butler, F. R., \& Zakari, N. (2005). Grandparents parenting grandchildren: Assessing health status, parental stress, and social supports. Journal of gerontological nursing, 31(3), 43-54. https://doi.org/10.3928/0098-9134-20050301-09

Casey, A. E. Foundation. (2012). Stepping up for kids: What government and communities should do to support kinship families. Retrieved from https://www.aecf.org/m/resourcedoc/AECF-SteppingUpForKids-2012.pdf

Casper, L. M., \& Bryson, K. (1998). Co-resident grandparents and their children: Grandparent maintained families. Population Division Technical Working Paper (No: 26). Washington DC: U.S. Bureau of the Census.

Child Welfare Information Gateway. (2016). Kinship caregivers and the child welfare system. Washington, DC: U.S. Department of Health and Human Services, Children's Bureau.

Collins, S. M., Fruhauf, C. A., \& Bundy-Fazioli, K. (2016). Concerns and supports of grandfamilies using formal services: Do they have the help they need?. GrandFamilies: The Contemporary Journal of Research, Practice and Policy, 3(1), 1-35.

Collins, W. L. (2011). A strengths-based support group to empower African American grandmothers raising grandchildren. Social Work and Christianity, 38(4), 453-466.

Cooper, C. (2012). Kinship Families: Grandparents and other relatives as primary caregivers for children. International Journal of Childbirth Education, 27(4), 27-31.

Dolbin-MacNab, M. L. (2006). Just like raising your own? Grandmothers' perceptions of parenting a second time around. Family Relations, 55(5), 564-575. https://doi.org/10.1111/j.1741-3729.2006.00426.x

Dunn, B., \& Wamsley, B. (2018). Grandfamilies: Characteristics and needs of grandparents raising Grandchildren. Journal of Extension, 56(5), n5.

Ellis, R. R., \& Simmons, T. (2008). Coresident grandparents and their grandchildren: 2012. Journal of Societal \& Social Policy, 7, 53.

Fuller-Thomson, E., \& Minkler, M. (2003). Housing issues and realities facing grandparent caregivers who are renters. The 
Are grandparents raising grandchildren ...

Gerontologist, 43(1), 92-98. https://doi.org/10.1093/geront/43.1.92

Gardiner, J. (2015). Utilizing family life education as a resource for grandparents raising grandchildren: A qualitative study (Unpublished Doctoral dissertation). Kansas State University, KS.

Generations United. (2018). New law will help the growing number of grandparents raising grandchildren. Retrieved from https:/www.gu.org/press_releases/new-law-will-help-the-growing-number-of-grandparents-raising-grandchildren/

Gibson, P. A., \& Singh, S. (2010). Let's help caregivers and children in informal kinship care: De facto custodian legislation. Child welfare, 89(3) 79-97.

Grinstead, L. N., Leder, S., Jensen, S., \& Bond, L. (2003). Review of research on the health of caregiving grandparents. Journal of Advanced Nursing, 44(3), 318-326. https://doi.org/10.1046/j.1365-2648.2003.02807.x

Hill, R. (1958). 1. Generic features of families under Stress. Social casework, 39(2-3), 139-150. https://doi.org/10.1177/1044389458039002$\underline{318}$

Landry-Meyer L., \& Newman, B. (2004). An exploration of the grandparent caregiver role. Journal of Family Issues. (25) 8, $1005-1025$. https://doi.org/10.1177/0192513X04265955

Lee, Y., \& Blitz, L. V. (2014). We're GRAND: A qualitative design and development pilot project addressing the needs and strengths of grandparents raising grandchildren. Child \& Family Social Work, 21(4), 381-390. https://doi.org/10.1111/cfs.12153

Lewis, J. P., Boyd, K., Allen, J., Rasmus, S., \& Henderson, T. (2018). “We Raise our Grandchildren as our Own:" Alaska native grandparents raising grandchildren in Southwest Alaska. Journal of Cross-Cultural Gerontology, 33(3), 265-286. https://doi.org/10.1007/s10823-018-9350-z

McCubbin, H. I., \& Patterson, J. M. (1983). The family stress process: The double ABCX model of adjustment and adaptation. Marriage \& family review, 6(1-2), 7-37. https://doi.org/10.1300/J002v06n01_02

Monahan, D. J., Smith, C. J., \& Greene, V. L. (2013). Kinship caregivers: Health and burden. Journal of Family Social Work, 16(5), 392402. https://doi.org/10.1080/10522158.2013.832464

Ohio Department of Job and Family Services. (2017). Ohio resources guide for relatives caring for children (JFS Report: 80146) Retrieved from http://www.co.warren.oh.us/ChildrenServices/Care/GuideBook.pdf

Ohio Grandfacts. (2021) States fact sheet for grandfamilies. Retrieved from https://www.grandfamilies.org/Portals/0/State $\% 20$ Fact $\% 20$ Sheets/Ohio\%20GrandFacts\%20State\%20Fact $\% 20$ Sheet $\% 202021 \%$ 20Update.pdf

Pandialagappan, T., \& Ibrahim, R. (2018). Theories of grandparental stress. Journal of Business and Social Review in Emerging Economies, 4(1), 101-106. https://doi.org/10.26710/jbsee.v4i1.372

Patterson J. (1988). Families experiencing stress: The family adjustment and adaptation response model. Family Systems Medicine 5(2), 202-237. https://doi.org/10.1037/h0089739

Peterson, T. L. (2018). Grandparents raising grandchildren in the African American community. Generations, 42(3), 30-36.

Porterfield, F. K. (2007). Family coping and adaptation among grandparents rearing grandchildren (Unpublished doctoral dissertation). Montana State University-Bozeman, MT.

Rausch, E. (2016). An exploration of subsidized grandfamily housing in the United States: What works (Unpublished doctoral dissertation). University of Minnesota, MN.

Ravitch, S. M. \& Carl, N. M. (Ed.). (2016). Qualitative research: Bridging the conceptual, theoretical and methodological. Thousand Oaks, CA: Sage.

Sands, R. G., \& Goldberg-Glen. R. S. (2000). Factors associated with stress among Grandparents raising their grandchildren. Family Relations, 49(1), 97-105. https://doi.org/10.1111/j.1741-3729.2000.00097.x

Smith, S. R., \& Hamon, R. R. (Ed.). (2017). Exploring Family Theories. Oxford: University Press.

Sutphin, S. T. (2015). Using Kinship Navigators to assess the needs of kinship caregivers. GrandFamilies: The Contemporary Journal of Research, Practice and Policy, 2(1), 50-74.

Van Etten, D., \& Gautam, R. (2012). Custodial grandparents raising grandchildren: Lack of legal relationship is a barrier for services. Journal of gerontological nursing, 38(6), 18-22. https://doi.org/10.3928/00989134-20120509-02

White, J. M., Klein, D. M., \& Martin, T. F. (Ed.). (2015). Family theories an introduction. Thousand Oaks, CA: Sage.

Whitley, D. M., Lamis, D. A., \& Kelley, S. J. (2016). Mental health stress, family resources and psychological distress: A longitudinal mediation analysis in African American grandmothers raising grandchildren. Journal of Clinical Psychology, 72(6), 563-579. https://doi.org/10.1002/jclp.22272 